\title{
La sirvienta y el luchador. Una interpretación ${ }^{1}$
}

\section{(La sirvienta y el luchador: An Interpretation)}

\section{Margarita Rojas G. ${ }^{2}$ \\ Universidad Nacional, Costa Rica}

\section{Flora Ovares ${ }^{3}$}

Universidad Nacional, Costa Rica

\begin{abstract}
RESUMEN
Este estudio se refiere a la cuarta novela de la serie sobre la familia Aragón, que Horacio Castellanos Moya empezó en 2003 y finalizó en 2013. Todas cuentan la historia política de El Salvador desde 1944 y en casi todas se menciona un acontecimiento: el secuestro y el asesinato de Alberto Aragón hijo, que finalmente se narra en La sirvienta y el luchador. Esto se lleva a cabo con una aparente simplicidad, que esconde una hábil manipulación de los recursos narrativos. Esa complejidad textual requiere una interpretación que vaya más allá de la referencia histórica y rescate el valor literario del texto.
\end{abstract}

\begin{abstract}
This study discusses the fourth novel in the series on the Aragón family, begun by Horacio Castellanos Moya in 2003 and completed in 2013. All the novels refer to the political history of El Salvador since 1944, and nearly all mention one event: the kidnapping and murder of the son of Alberto Aragón, which is finally narrated in La sirvienta y el luchador. This is carried out with an apparent simplicity that hides a skillful manipulation of narrative resources. The textual complexity requires an interpretation which goes beyond historical references and addresses the literary value of the text.
\end{abstract}

1 Recibido: 2 de diciembre de 2017; aceptado: 2 de abril de 2018.

2 Escuela de Literatura y Ciencias del Lenguaje. Correo electrónico: mrojas@una.cr

3 Escuela de Literatura y Ciencias del Lenguaje (académica jubilada). Correo electrónico: floraovares@yahoo.com 
Palabras clave: literatura centroamericana, novela salvadoreña, novela sobre la guerra

Keywords: Central American literature, Salvadoran novel, war novel

Hubo muchas versiones pero el crimen nunca se aclaró.

Horacio Castellanos Moya, La sirvienta y el luchador

La muerte es un acontecimiento común en la narrativa de todos los tiempos; algunos la han interpretado como una transformación en el viaje del héroe; también se la tomado como el hecho que da inicio a la investigación en el género policial. En las novelas de Horacio Castellanos Moya, sin embargo, se trata generalmente de un hecho violento, gratuito y descrito con detalles macabros y a veces repulsivos. En la novela Baile con serpientes ${ }^{4}$, las serpientes que acompañan a un sociólogo desempleado en una orgía criminal en la que muchos asesinatos no ofrecen justificación, no obedecen ni a la venganza ni la defensa. En Desmoronamiento ${ }^{5}$, cuyas dos partes se titulan «La carpeta de la guerra»y «La carpeta del crimen», la historia se centra en los últimos días de la vida de Lena Mira Brossa; también se menciona el fallecimiento de su esposo Erasmo, ocurrido unos años antes; la primera parte termina con la noticia del asesinato del presidente John F. Kennedy. Hay también varias referencias a otra muerte en la familia, el asesinato de Clemen, el yerno de Lena y Erasmo. Más allá de las muertes de los personajes principales, esta segunda novela narra el fin de una dinastía familiar, la dispersión de sus propiedades e incluso la destrucción de sus recuerdos.

La saga de la familia Aragón comprende cinco novelas: Donde no estén ustedes, Tirana memoria, La sirvienta y el luchador, Desmoronamiento y El sueño del retorno, que fueron apareciendo entre 2003

4 Horacio Castellanos Moya, Baile con serpientes (1996), 2a edición (Barcelona: Tusquets, 2002).

5 Horacio Castellanos Moya, Desmoronamiento (México, D. F: Tusquets, 2006). 
y $2013^{6}$. En estas llama la atención la reiteración de un asesinato, el de Albertico Aragón, nieto de Pericles Aragón, y de su esposa Brita. Este crimen, aludido a lo largo de todas las novelas, se narra con mayor detalle y se explica en la penúltima novela. En Donde no estén ustedes se contextualiza el secuestro de la pareja durante los tiempos de la insurrección nacional en El Salvador ${ }^{7}$, de la cual se refieren algunos acontecimientos como el caso del asesinato de Mario Zamora. Por otro lado, la captura de los jóvenes se atribuye a la presunta delación de Henry Highmont, amigo de Alberto Aragón, padre de Albertico. Highmont lo habría traicionado a causa del adulterio de su amigo con su esposa.

En El sueño del retorno se sugiere la responsabilidad del Partido Comunista de El Salvador en la muerte de los muchachos. Además, se cuenta la estadía de Albertico en Costa Rica antes de su partida hacia El Salvador, para la celebración familiar del año nuevo. En esa actividad un periodista norteamericano le aconseja no ir a ese país y a la pregunta de su primo Erasmo, sobre su decisión, este le contesta «"voy" por pendejo»: Albertico vuelve a El Salvador a sabiendas del riesgo que corre. De igual manera, al final de su historia, Erasmo repite el viaje de aquel cuando sale de México hacia El Salvador y consciente de los riesgos de su decisión, reconoce la existencia de un

6 Horacio Castellanos Moya, Donde no estén ustedes (México, D. F: Tusquets, 2003); Desmoronamiento (2006); Tirana memoria (Barcelona: Tusquets, 2008); La sirvienta y el luchador (México, D. F: Tusquets, 2011); y El sueño del retorno (México, D. F: Tusquets, 2013).

7 En marzo de 1980, después de recibir frecuentes amenazas de muerte, el arzobispo Óscar Arnulfo Romero es asesinado durante la celebración de una misa ante la presencia de cientos de feligreses. El mismo mes miembros de grupos paramilitares asesinan al procurador general Mario Zamora, integrante de la dirección demócrata-cristiana; meses después es el asesinato de cuatro religiosas estadounidenses y el 11 de noviembre un contingente de la Guardia Nacional secuestra a Abdala Antonio Handal, hermano de Sahfik Handal, secretario general del Partido Comunista de El Salvador y a otras personas. En octubre el Partido Comunista y el Partido Revolucionario de los Trabajadores Centroamericanos (PRTC) se unen en el Frente Farabundo Martí para la Liberación Nacional (FMLN). El 10 de enero de 1981 el FMLN convoca a la ofensiva general o insurrección final, destinada a provocar un levantamiento popular para derrocar la Junta Revolucionaria de Gobierno; se inició una guerra civil que duró doce años. En noviembre de 1989 los militares asesinaron a seis jesuitas y finalmente en enero de 1992 se firmaron los Acuerdos de Paz. Cfr. Luis A. González, «El Salvador de 1970 a 1990 política, economía y sociedad», Realidad 67 ((1999): 43-61). DOI: https:/doi.org/10.5377/realidad.v0i67.4844. 
vínculo entre el muerto y él mismo: «mi vida estaba tan atada a la de mi primo» (El sueño del retorno, 130).

El asesinato de Albertico y Brita es el episodio que abre y concluye La sirvienta y el luchador. Este crimen se narra desde ángulos diferentes, por ejemplo, el del padre del joven, quien emprende una búsqueda de la pareja a lo largo de la ciudad y en sus afueras. También se cuenta desde la perspectiva de algunos personajes cercanos a la familia y las víctimas, como María Elena, empleada doméstica de los Aragón. La captura, la tortura y la muerte de los jóvenes es, para ella, un hecho vinculado con desapariciones de otros familiares:

Albertico y Brita deberían irse del país, regresar a Costa Rica, y don Betío también. Esta situación tan horrible no es para ellos. Es imprudente tentar al Diablo, y con la mala suerte de esa familia: primero el cáncer de doña Haydée, luego el asesinato de don Clemen, el hermano de don Betío, y después el suicidio de don Pericles...Mejor que los muchachos se vayan del país (La sirvienta y el luchador, 91).

\section{Dos historias paralelas}

El secuestro y el asesinato de la pareja forman parte de la guerra civil; sin embargo, en la novela hay una sutil división y cada hecho - secuestro o guerra - constituye una historia que se narra de forma relativamente separada. Por ejemplo, las secciones que relatan la situación del Vikingo $0^{8}$ y María Elena en el hospital se alternan con otras tantas del regreso de Joselito a su casa y del encuentro de Rita con su hijo Leandro. La insurrección está contada principalmente alrededor de Belka y Joselito, hija y nieto de María Elena.

La mayor parte de los personajes se agrupa según participan en una o en otra historia: el Vikingo y María Elena solo forman parte del secuestro; Joselito no tiene que ver con el secuestro y solamente actúa

8 En El Salvador hubo un practicante de lucha libre con el mismo nombre, nacido en 1944, un «rudo salvadoreño» que aparece retratado en un diario guatemalteco. Véase $<\mathrm{http}$ ://clubdelabuenaestrella .blogspot.com/2016/09/un-vikingo-en-las-arenas-de-la-lucha.html>. 
en varias acciones militares en las calles de la ciudad; María Elena se cruza con él en algunas ocasiones; los miembros de la familia Aragón solamente participan en la historia del secuestro; la gorda Rita y sus hijos están relativamente al margen de las dos historias principales.

Así como se separan las dos historias, los personajes pertenecen a posiciones políticas opuestas: del lado de los militares están el Vikingo, los torturadores, Rita y su hijo, Belka y el médico Barrientos; del lado de los insurrectos están Joselito, Albertico y su esposa y varios integrantes de la familia Aragón. Aunque los caminos que recorre cada personaje tienen metas distintas a veces se cruzan. Así sucede cuando María Elena reconoce a Joselito en el mesón que habitaba el Vikingo. Mientras ella visitaba al enfermo, su nieto llegó a matarlo en un operativo político.

\section{Triturar y engullir}

A pesar de la trascendencia de los acontecimientos, la novela empieza con una actividad que en apariencia no tendría relación con los hechos políticos y bélicos. La narración se inicia con una referencia a la acción de comer: el Vikingo y los tres macheteros (torturadores) se encuentran a la hora del almuerzo en la venta de la gorda Rita, donde asedian a la hija de la mujer. Además de la comida, la descripción insiste en que todos carecen de dientes o estos están podridos.

El apodo de los macheteros proviene de su papel en el proceso de tratamiento de los prisioneros de guerra: una vez ingresado a la fuerza en el Palacio Negro y obtenida mediante maltratos la confesión del prisionero, a ellos les corresponde tasajearlos, reducirlos a pedazos, con machetes, para que luego otros lleven a tirar su cadáver a una zona fuera de la ciudad. «No les tengo miedo - dice la Gorda (...) - Porque no los ha visto destazando... Hacen cantar al más valiente tras el primer tajo» (14-15).

Los dientes humanos cumplen diversas funciones: cortar, sostener y triturar; los macheteros realizan las funciones de los tres tipos de 
dientes ${ }^{9}$. El proceso de captura de los oponentes políticos y su tortura con el fin de obtener información sigue un patrón equivalente al de la ingestión y la expulsión de la comida: «Va hacia la cloaca número cinco. Tiene media hora para revisar a la recién llegada; cuando vuelva de la pesca ella seguramente ya estará en manos de los macheteros (...) Es su trabajo: el machacarlos, sacarles la mierda, nada más. Pronto vendrán por ellos para llevarlos a la ópera, que es donde cantan sus secretos, y enseguida serán carne para los macheteros» (23). La comparación de un proceso de digestión con la tortura se completa en la mención de las últimas celdas en los sótanos como las cloacas, vecinas de la sección «la ópera», donde los prisioneros «cantan».

La estructura de varias plantas del Palacio Negro, centro del poder, subraya la isotopía de la ingestión humana: «las escaleras: las que conducen a la planta alta son anchas y están iluminadas; las que conducen a los sótanos parecen una boca oscura» (68).

Las referencias a la comida se repiten con frecuencia a lo largo de la novela: se describe en detalle el comedor de Rita, su rutina cotidiana y los alimentos que prepara (115). Se explica que antes de instalar el comedor en la cochera de una casa antigua (154), Rita trabajó por tres años en una venta de tortillas (186). Muchos de los personajes ingieren bebidas y alimentos en diferentes momentos. María Elena come en la casa de la familia Aragón (104); Joselito frecuenta el cafetín universitario, «un galerón de madera, con techo alto de láminas de zinc» (147); se describe minuciosamente la comida que Belka prepara para su hijo.

Además, el acto de ingerir alimentos se relaciona con dos cosas: el deseo sexual y el intercambio de información. Joselito prefiere asistir al cafetín de la Facultad de Humanidades porque allí acuden

9 Se dice que «nuestros incisivos cortan los alimentos, nuestros premolares los mantienen en su lugar mientras que nuestros caninos los hacen jirones, nuestros molares los muelen en fragmentos digeribles. Todas estas actividades han dado lugar al simbolismo de la agresión, de arrancar de un golpe porciones de la existencia para asegurar su sobrevivencia, su adaptación y su creencia; masticar la sustancia de la vida a fin de que esta sea asimilada», Ami Ronnberg y Kathleen Martin, eds., Le livre des symboles (Colonia: Taschen, 2011) 370, traducción de Rojas y Ovares. 
muchachas; los macheteros desean a Marilú, la hija de Rita y la molestan durante la comida. Su madre la defiende y provoca la irritación del Vikingo, quien piensa que «le pedirá al machetero gordo que la destace para venderla como carne para picadillo y con la niña se quedará él» (17). Más adelante, le confiesa a María Elena: «Yo la deseé a usted un montón (...) Cierro los ojos y la puedo ver cuando llegaba al comedor de La Rábida a recoger las tortillas» (251).

\section{Los informantes ocultos}

Así como la comida se ingiere o se expulsa, la información se extrae de la gente mediante diversos procedimientos. De ahí la relevancia de dos espacios: el comedor de Rita y el hospital. El comedor había sido fruto de una iniciativa del misterioso Leandro, hijo de Rita, el cual le proporcionó el dinero necesario para el negocio. Le indicó dónde abrirlo, cerca del Palacio Negro (186 y 189), y le puso la condición de informar acerca de las conversaciones de sus parroquianos, la mayoría provenientes de esa institución. Cuando Belka le prepara la comida a su hijo - militante clandestino - le cuenta al mismo tiempo algo de mucha importancia para ella, que es el cambio de situación laboral y su proximidad con los militares.

Los recorridos de Joselito, Belka y María Elena, sobre todo, los llevan a muchos lugares de la ciudad, unos de los cuales son los hospitales. Belka trabaja en el Hospital Rosales, donde llevan heridos a María Elena y el Vikingo, aunque quiere irse de allí y busca trabajo en un hospital de los militares (211). De las clínicas médicas secuestran al doctor Chente Alvarado, amigo de la familia Aragón, mientras que el esposo de Luisa, la jefa de Belka, trabaja en la Clínica Popular «donde según el rumor se agrupan los médicos que tienen simpatías por los subversivos» (145).

El hospital es un espacio que se acerca menos a la comida que a la enfermedad y la muerte; en oposición a lo que sucede en la fonda, la gente no ingiere alimentos por dieta o por pérdida del apetito, como 
se ve durante la estadía de María Elena (182 y 241). El Vikingo temía hospitalizarse porque consideraba que de ahí saldría otro «muerto»: «En ese hospital "Hospital Militar" es donde yo debería estar, pero me mandaron para acá porque creen que ya soy un desperdicio, saben que no sobreviviré» (244).

\section{Investigación y secreto}

En una situación de guerra que divide la sociedad en dos bandos todos esconden información sobre los hechos y las identidades. Casi todos los personajes callan lo que sucede y no revelan lo que saben, sino que guardan información ocultan una identidad secreta. El trabajo político de la clandestinidad se basa en el secreto, como el caso de Joselito; este no cuenta ni a su madre ni a sus compañeros que su abuela lo descubrió como militante. Al Vikingo lo mortifica el secreto de María Elena y a ella, como a los integrantes de la familia Aragón, la identidad del asesino de uno de sus integrantes: Clemente Aragón (Clemen). María Elena y Belka, por otro lado, no revelan quiénes son los padres de sus respectivos hijos; esta última tampoco habla de su relación con Barrientos, ayudante de los militares; María Elena no da toda la información a la familia Aragón ni con respecto a Clemen ni acerca de lo que sabe del secuestro de Albertico ${ }^{10}$. Rita y su hijo Leandro guardan su identidad de informantes del gobierno; el médico Barrientos no le explica a Belka sobre los trabajos extra que tendría que hacer en el nuevo puesto y ella desconoce la localización del hospital militar.

Otro misterio al que se alude en varias novelas es el asesinato de Clemen, que ocurre en los años sesenta y se había narrado en Desmoronamiento. Mientras el Vikingo insiste en conocer los pormenores de la relación entre Clemen y María Elena, esta trata de averiguar lo

10 «Ella le cuenta los hechos [...] Pero no refiere el zarpazo del gordo zarco que capturó a Albertico, ni la aparición salvadora del Chicharrón, ni mucho menos la visión del joven embozado que lanzaba el coctel Molotov...», Castellanos Moya, La sirvienta y el luchador, 101. 
sucedido al nieto de su antiguo patrón. Insiste en conocer la verdad de las cosas y para ello recorre incansablemente las calles de la ciudad en busca del paradero de los jóvenes e interroga a posibles testigos. Así, mientras ella trata de resolver el crimen político del presente, el hombre sigue anclado en el crimen pasional del pasado.

La perspectiva que orienta la investigación en la novela es la de ese personaje; María Elena es quien averigua la verdad de ambos asesinatos. Desde que secuestran a los jóvenes investiga, deduce, establece relaciones sobre todo de las acciones de los policías. En ese proceso, la mujer se desplaza por toda la ciudad, en su recorrido se lastima el pie, pero así se acerca a la realidad del país y se coloca en una posición intermedia entre los dos bandos en pugna ${ }^{11}$.

Después de la balacera en casa del Vikingo, este y María Elena son trasladados en la misma ambulancia y se encuentran en camas contiguas en el hospital. María Elena se asusta cuando se percata del hombre a su lado; en ese momento tiene lugar una escena de reconocimientos cruzados, primero por parte de la enfermera que le lleva el desayuno a ella, luego cuando Joselito, quien visitaba a su abuela, reconoce al Vikingo, momento en que ella confirma lo que sospechaba del nieto.

En el hospital María Elena también entiende que el Vikingo participó en el secuestro de Albertico; al mismo tiempo descubre cómo había participado el policía y finalmente comprende que este había vigilado y matado a Clemen, por celos y por vengar la seducción de ella (253-254).

Entonces, los hospitales resultan lugares de encuentro casual, donde con frecuencia se obtiene información. En su última conversación con el Vikingo, cuando este ya no puede retener la comida dentro de su cuerpo, finalmente revela el secreto que había mantenido

11 Se ha dicho que para acceder a un nuevo conocimiento es necesario descalzarse, porque el pie es el contacto con el suelo o el piso; es decir, con la realidad. Además, la sandalia se relaciona con Hermes, el intermediario, el mensajero entre lo invisible y lo visible, cfr. Jean Chevalier y Alain Gheerbrant, Diccionario de los símbolos (Barcelona: Herder, 1986) 909. 
callado toda la vida respecto al asesinato de Clemen. Desde antes, sin embargo, ya María Elena se había percatado de que el Vikingo había cambiado: «Ella ya se ha acostumbrado a la penumbra. No es el envejecimiento ni lo cadavérico en el rostro: algo ha cambiado en él, como si hubiera otro en la mirada» (80).

\section{Espacios interiores y espacios exteriores}

Engulliry devorar, vomitar y expulsar construyen una oposición entre un espacio interior y otro exterior. En esta novela el acto de comer no posee la connotación de nutrición ni de socialización. Se trata más bien de una mera actividad de introducir materialmente algo dentro del cuerpo. Debido a su enfermedad, que no quiere aceptar, el cuerpo del Vikingo rechaza que introduzca en él más comida. Aunque insista en comer, el cuerpo, enfermo, la rechaza, la vomita. Además, por su enfermedad el hombre siente dolores y espasmos dentro de sí, escupe pus y tiene mal aliento. De esta forma el individuo se configura como un cuerpo, cuya interioridad encierra enfermedad y muerte. El cuerpo humano e incluso los edificios como el Palacio Negro, aparecen como una especie de contenedores a los que se introduce comida o, si se trata de prisioneros, en las «cloacas» se les maltrata con la introducción de objetos en el ano.

Esta cercanía entre espacios y seres humanos explica que la boca del Vikingo huela mal, y que algo similar suceda con la ciudad: durante el recorrido de María Elena por la urbe se subraya el calor, el sol y el aire hediondo o con olores; en la catedral «hay un olor denso en el aire, como a desinfectante» (120). Antes de llegar al edificio donde vive el Vikingo, se pasa por un río de aguas negras; afuera y adentro de su habitación apesta, incluso María Elena tiene que taparse la nariz: «Apesta el aire por la cercanía del río, infectado por las aguas negras de la ciudad» (76). El lugar es un mesón de varios cuartos: 
Son dos hileras de habitaciones, seis de cada lado, frente a frente, separadas por un corredor destechado en el medio. Las paredes mugrosas, descascaradas; el corredor sucio, con desperdicios y basura, mohoso, como si nadie lo hubiera barrido en meses. Y el aire, más hediondo (...) aquí apesta a muerto (...) percibe la fetidez y se cubre con un pañuelito la nariz (77-78).

Los hospitales son espacios que acogen a las personas para «extraerles» la enfermedad. Ese proceso de curación resulta interrumpido por la violencia militar, que irrumpe en las salas de operación para secuestrar a los heridos e incluso al personal médico.

Alos oponentes capturados los introducen en el sótano del Palacio Negro, son tragados como la comida; en las celdas los «procesan», los mastican, los torturan para que los macheteros los corten y los hagan desaparecer. Lo que resulta de todo es la muerte.

\section{El monstruo enfermo}

El epígrafe de la novela apunta a la significación de «atrapar» y de un «tiempo malo»: «Porque el hombre tampoco conoce su tiempo: como los peces que son atrapados en la mala red, y como las aves que se prenden en lazo, así son enlazados los hijos de los hombres en el tiempo malo, cuando cae de repente sobre ellos» (Eclesiastés).

El Vikingo se encuentra en la etapa final de su vida y es incapaz casi de realizar su oficio de torturador. Constantemente se queja de su situación:

Todos quieren enviarlo al hospital o a su habitación o la morgue, a donde sea. Sacarlo de circulación, como si ya no sirviera como si no hiciera bien su trabajo, como si en nada fuera útil su experiencia, como si ser el más viejo no tuviera valor. No lo llevan a las redadas porque «La presa se le puede escapar» (21). 
La debilidad del Vikingo y la merma de sus capacidades depredadoras se evidencian en su dentadura: «Le faltan un incisivo, un colmillo y casi todas sus muelas» (13-14). También otros personajes que como el Vikingo «trabajan» para la seguridad del Estado, han perdido parte de sus facultades: los macheteros tienen los dientes podridos. Se ha dicho que el diente es un instrumento de posesión y agresividad y, por lo tanto, su ausencia es sinónimo de pérdida de la juventud y la capacidad de defensa:

perder los dientes es ser desposeído de fuerza agresiva, de juventud, de defensa; es un símbolo de frustración, de castración, quiebra. Es la pérdida de la energía vital (...) El diente es instrumento del tomar posesión o incluso de la asimilación: la muela que tritura, para proporcionar alimento al deseo ${ }^{12}$.

En el caso del Vikingo, la expulsión viene acompañada de fetidez y dolores. La decadencia física del personaje se describe también mediante acciones como escupir pus, expulsar mal aliento: todo esto le sale de su interioridad, él es un cuerpo que encierra enfermedad y muerte, dolores y espasmos. Por un lado, el Vikingo se debilita; por otro, la guerra recrudece: hay un intento de ajusticiamiento del que participan Joselito y otro compañero en contra del policía, que está recluido en su habitación. Paralelamente se dan otras batallas y atentados en las calles de la ciudad los cuales involucran a María Elena, Belka y Joselito.

El recrudecimiento de la guerra tiene como consecuencia la ampliación del perímetro de seguridad del Palacio Negro: el monstruo trata de defenderse y engulle los espacios aledaños. Primero se amplía dos cuadras el perímetro de seguridad y luego este abarca la zona donde se encuentra el comedor de la gorda Rita. «Ahora todo se pudrió, ya no pueden estar tranquilos fuera del Palacio» (35).

12 Chevalier y Gheerbrant, 417. 
El cuerpo del Vikingo resulta equivalente a la dictadura militar salvadoreña representada en el Palacio Negro. Ambos son cuerpos malolientes e infectados que ya no son capaces de ocultar su enfermedad y cuya pudrición se extiende por toda la ciudad. Ambos vomitan los secretos y los crímenes que no pueden esconder.

De igual manera, el poder militar no es capaz de ocultar los rastros de su barbarie. Las órdenes militares indicaban que, a diferencia de los cuerpos de los otros prisioneros, que eran lanzados por el risco, los de Albertico y Brita debían ser sepultados: «El capitán ordenó que a la rubia y al del afro los enterremos donde nadie los encuentre») (261, subrayado nuestro). Sin embargo, los encargados no logran cumplir la orden pues ninguno lleva las palas necesarias y el relato se cierra con una pregunta sobre su propia incapacidad.

La dictadura no puede ocultar las huellas de sus crímenes dado el grado de su putrefacción; paralelamente, la escritura literaria debe acompañar el proceso de la enfermedad y la muerte del cuerpo enfermo. El producto final no es placentero sino doloroso, pero es necesario para enfrentar al lector a las heridas de la historia que todavía están abiertas. 